\author{
The Pennsylvania State University \\ College of Earth and Minerals Sciences \\ Department of Materials Science and Engineering \\ University Park, PA 16802
}

\author{
Project Entitled
}

\title{
INFLUENCE OF POINT DEFECTS ON GRAIN BOUNDARY DIFFUSION IN OXIDES
}

Proposed Duration:

Requested Starting vate:

Principal Investigator

phone (814-865-9921)

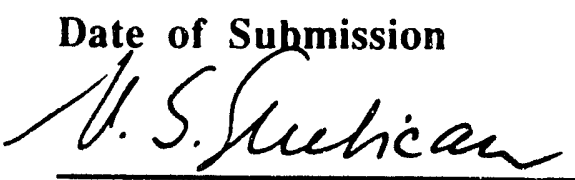

v. S. Stubican

Professor Materials Sci. \& Eng.

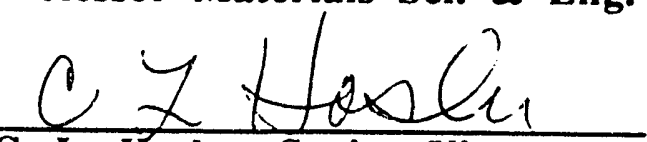

C. L. Hosler, Senior Vice

President for Research and

Dean of the Graduate School

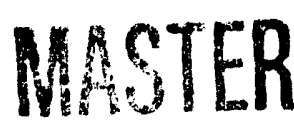

BISTRIBUTION OF THIS DOCUMEMT IS UNLIMITEM
12 months

July 1, 1992

V. S. Stubican

March 15, 1991

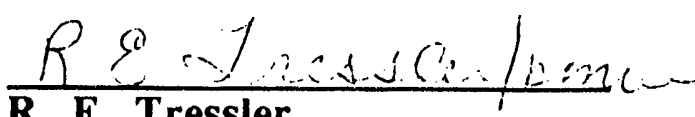

R. E. Tressler

Head Department Materials Sci.

\& Eng.

\section{DISCLAIMER}

This report was prepared as an account of work sponsored by an agency of the United States Government. Neither the United States Government nor any agency thereof, nor any of their employees, makes any warranty, express or implied, or assumes any legal liability or responsibility for the accuracy, completeness, or usefulness of any information, apparatus, product, or process disclosed, or represents that its use would not infringe privately owned rights. Reference herein to any specific commercial product, process, or service by trade name, trademark, manufacturer, or otherwise does not necessarily constitute or imply its endorsement, recommendation, or favoring by the United States Government or any agency thereof. The views and opinions of authors expressed herein do not necessarily state or reflect those of the United States Government or any agency thereof. 
For technical assistance contact:

V. S. Stubican

Professor

Materials Science and Engineering

230 Steidle Building

University Park, PA 16802

Telephone (814) 865-9921

For financial assistant contact:

Robert Killoren

Director, Sponsored Programs

284 Calder Way

University Park, PA 16802

Telephone (814) 863-0587 


\section{Table of Contents}

I. Repor for the Period: July 1, 1990-March 1, 1992

II. Future Work 4

III. Papers Published and Presented 9

IV. Present and Pending Support 10

V. Budget for the Period July 1, 1992 - June 30, 1993

VI. Appendix (Paper submitted for publication) 
I. Report Work on the project entitled "Influence of Point Defects on Grain Boundary Diffusion in Oxides", Period of July 1, 1990 - March 1, 1992).

Personnel:

1. Mr. Larry Carinci, graduate student in Cer. Sci. (B. S. Penn State, 1990)

2. Dr. M. Trubelja, Post-doctoral Fellow (Ph.D. Penn State, 1985) 6\% of time.

3. V. S. Stubican, Principal Investigator of $15 \%$ of time.

During the period July 1, 1990 - March 1, 1992. (total 21 months) the following research was accomplished.

Experimental Part

The equipment which is used for the annealing of samples and diffusion runs at different oxygen pressures $\left(\mathrm{P}_{\mathrm{O}_{2}}=10^{-1}-10^{-16} \mathrm{MPa}\right)$ was rebuilt and recalibrated.

To study influence of point defects on the grain boundary diffusion in $\mathrm{NiO}$ two types of starting material were used:

(i) Bicrystals of $\mathrm{NiO}$ which were obtained by using an arc image furnace. These crystals were characterized for oreintation by using $\mathrm{x}$-ray back reflection Laue technique. The amount of bulk impurities was determined by using semiquantitative emission spectroscopy and the following impurities were detected: $\mathrm{Si}<$ 15, Gr 20, $\mathrm{Fe}<20, \mathrm{Co}<20, \mathrm{Al}<20, \mathrm{Cu}<5, \mathrm{Ti}<10$ p.p.m by weight.

(ii) Polycrystalline NiO films with $\sim 100 \%$ of theoretical density were prepared the following way: $\mathrm{NiO}$ single crystals were used as substrates, and $\mathrm{Ni}$-foils (purity $99.999 \%$ ) of the thickness 25 or $50 \mu \mathrm{m}$ were fixed on NiO single crystal substrates. $\mathrm{Ni}$-foils were then oxidized in pure $\mathrm{O}_{2}$ at $1250^{\circ} \mathrm{C}$ for $18 \mathrm{hrs}$. Uniform polycrystalline $\mathrm{NiO}$ films (average thickness $60-80 \mu \mathrm{m}$ ) on $\mathrm{NiO}$ single crystal substrates were obtained. SEM investigation showed the films did not have any porosity and the average grain size was $7-10 \mu \mathrm{m}$. To remove grooves between grains films were polished with diamond paste. Samples were equilibrated for 1824 hours at $750^{\circ} \mathrm{C}$ in a desired atmosphere $\left(\mathrm{P}_{\mathrm{C}_{2}}=10^{-1}-10^{-16} \mathrm{MPa}\right)$. Co-metal was 
sputtered on equilibrated samples and diffusion annealing was done for 1-3 hrs, at the same oxygen partial pressure as annealing. Diffusion profiles were determined by using SIMS.

We started also work with $\mathrm{NiO}$ bicrystals by using ${ }^{57} \mathrm{Co}$ isotope. Determination of diffusion profiles in this case was by a serial sectioning technique. To obtain volume diffusivity of Co-ion in $\mathrm{NiO}$ metallic Co was sputtered onto a surface of the $\mathrm{CoO}$ crystal which was previously equilibrated for $72 \mathrm{hrs}$ at the oxygen pressure under which diffusion was to be performed. After Co was oxidized at $\sim 250^{\circ} \mathrm{C}$ for a short time, volume (lattice diffusion runs were carried out under different oxygen partial pressures. Volume diffusion profiles were determined by using SIMS.

Results

Grain boundary diffusion data were evaluated by using Whipple's formula which was modified by Le Clair. Whipple's infinite-source and Suzuoka's finite source solution for the grain boundary diffusion give results which are very close $10 \%$.

Whipple's solution can be expressed as $\left.\alpha \mathrm{D}_{\mathrm{g} . b} \delta=\left(\partial \ln \bar{c} / \partial \mathrm{y}^{6 / 5}\right)^{-5 / 3}\left(4 \mathrm{D}_{\mathrm{v}} / \mathrm{t}\right)^{1 / 2}\right) 0.78^{5 / 3}$ where $\alpha$ is ${ }^{57} \mathrm{Co}$ segregation factor in $\mathrm{NiO}, \mathrm{D}_{\mathrm{g} . b .}$. grain boundary diffusion coefficient, $\overline{\mathrm{c}}$ specific activity of isotope, $y$ distance from the original surface, $D_{v}$ volume diffusion coefficient, and $t$ the time of anneal. In the case of the grain boundary diffusion of $\mathrm{Co}$ in $\mathrm{NiO}$ it is reasonable to assume that $\alpha=1$ because radii of $\mathrm{Co}^{2+}$ and $\mathrm{Ni}^{2+}$ ions are very close $\left(\mathrm{rCo}^{2+}=0.885 \AA\right.$, and $\mathrm{rii}^{2+}=0.834$ $\AA$ ). The value for $\delta$ was determined by Atkinson and Taylor to be 7-10 $\AA$. To determine $D_{v}$ for Co diffusion in $\mathrm{NiO}$ at different oxygen pressures $\mathrm{Co}$-ion was diffused at different oxygen pressures in $\mathrm{NiO}$ crystal which was previously annealed at the same oxygen pressures. Concentration profiles were determined by SIMS. One example of Co-ion lattice diffusion in $\mathrm{NiO}$ at $750^{\circ} \mathrm{C}$ is shown in Fig. 1. The straight line was obtained by the best fitting methoci and the absolute values of the volume diffusivity of the Co-ion in $\mathrm{NiO}$ were then calculated from the slopes of these plots.

The results are shown in Fig. 2. It can be not ?d that the volume diffusivity of Co-ion remains constant for $\mathrm{P}_{\mathrm{O}_{2}} \approx 10^{-15}-10^{-7} \mathrm{MPa}$ indicating that in this region volume diffusion was 
impurity controlled (extrinsic region). It is well known that $D_{v}=f \cdot N \cdot D_{v a c}$ where $f$ is the correlation factor, $\mathrm{N}$ mol fraction of vacancies and $\mathrm{D}_{\mathrm{vac}}$, diffusion coefficient of a vacancy. In the extrinsic region the number of nickel vacancies is basically determined by the concentration of higher valent impurities.

A strong increase in the volume diffusivity was observed at $\mathrm{P}_{\mathrm{O}_{2}}$ above $10^{-7} \mathrm{MPa}$ demonstrating that in this $\mathrm{P}_{\mathrm{O}_{2}}$ region the volume diffusivity of Co-ion is increasingly dependent on the amount of cation vacancies which are formed to compensate for the oxidation of $\mathrm{Ni}^{2+}$ ion to $\mathrm{Ni}^{3+}$ ion (intrinsic). The obtained results for the volume diffusion of $\mathrm{Co}$-ion in $\mathrm{NiO}$ were then used for the calculation of the grain boundary diffusion results.

In Fig. 3 a diffusion profile for the grain boundary diffusion of $\mathrm{Co}^{2+}$ in $100 \%$ dense polycrystalline $\mathrm{NiO}$ film is shown. The profile was obtained by determining the concentration of Co as a function of depth using SIMS technique.

Several grain boundary diffusion runs were made and the values for $D_{\text {g.b. }}$ were calculated using Whipple's formula with $\alpha-1$ and $\delta=10 \AA$. On Fig. 4 the results obtained are shown. Comparing Fig. 3 and Fig. 4 it is evident that the influence of the oxygen partial pressure on the lattice and grain boundary diffusion is similar. The extrinsic region can be observed in both cases below $\mathrm{P}_{\mathrm{O}_{2}} \simeq 10^{-7} \mathrm{MPa}$ at $750^{\circ} \mathrm{C}$. Above this oxygen partial pressure, both $\mathrm{D}_{\mathrm{v}}$ and $\mathrm{D}_{\text {g.b. }}$ increase is due to the predominant influence of vacancies formed to compensate oxidation of $\mathrm{Ni}^{2+} \rightarrow \mathrm{Ni}^{3+}$ ion (intrinsic region). Furthermore it is evident that grain boundary diffusion coefficient are more than 3-order of magnitude larger than volume diffusion coefficients. Two grain boundary diffusion coefficients were also determined by using $\mathrm{NiO}$ - bicrystals and ${ }^{57} \mathrm{Co}$ isotope. The results are shown on Fig. 4. The results obtained with polycrystalline films and bicrystals are quite close.

\section{Summary}

1. The influence of point defects on grain boundary diffusion Co-ion in NiO was studied by using dense polycrystalline films and bicrystals. Preparation of bicrystals and NiO-films is described. 
2. The grain boundary diffusion was studied at $750^{\circ} \mathrm{C}$ at partial pressure of oxygen. Two diffusion regions were found. At low oxygen pressures extrinsic diffusion was observed. Above $\mathrm{P}_{\mathrm{O}_{2}}=10^{-7} \mathrm{MPa}$ the influence of intrinsic point defects was detected.

3. It was determined that grain boundary diffusion was $>3$-orders of magnitude faster than volume diffusion. However, it seems that grain boundary diffusion is influenced by the point defects in a similar way as the volume diffusion. Quantitative analysis of the results obtained taking into account change in the number of defects with $\mathrm{P}_{\mathrm{O}_{2}}$ is now in progress.

\section{Future Work}

Our further work will continue along lines described in the original proposal. We intend to finish work on the influence of point defects on the grain boundary diffusion in NiO. Few more runs will be made using NiO bicrystals and ${ }^{57} \mathrm{Cr}$-isotope at high oxygen pressures. Grain boundary diffusion of ${ }^{57} \mathrm{Co}$ in $\mathrm{Fe}_{3} \mathrm{O}_{3}$ bicrystals will be then studied at different partial pressures of oxygen. To equilibrate the magnetite bicrystals prior to a diffusion run they will be annealed at a prefixed oxygen partial pressure using $\mathrm{CO} / \mathrm{CO}_{2}$ mixtures at $900-1100^{\circ} \mathrm{C}$. According to Dieckmann and Schmalzried 7-8 days of annealing is sufficient to equilibrate magnetite samples fully (for the low temperature runs the sample thickness will be brought down to $5 \mathrm{~mm}$ ). The ${ }^{57} \mathrm{Co}$ isotope in aqueous solution will be applied on the surface of bicrystals. After drying at about $120^{\circ} \mathrm{C}$ with an $\mathbb{R}$ lamp, two bicrystals will be sandwiched, held under slight pressure between alumina parts, and put in the furnace. The atmosphere and temperature in diffusion runs will be those of annealing runs. The oxygen partial pressure and the temperature will be measured simultaneously close to the sample with help of a solid state galvanic device using a $\mathrm{ZrO}_{2}$-cell and Pt-Pt 10\% Rh thermocouples respectively. After a diffusion anneal, the edges of the sample will be ground to eliminate any activity resulting from diffusion along the sides of the sample. The concentration profile (i.e., the average concentration. $c$ vs. depth) of the tracer will be determined by a serials sectioning technique. The result obtained will be compared with the lattice diffusion results and will be evaluated by consid ring the defect chemistry of $\mathrm{Fe}_{3} \mathrm{O}_{4}$ as influenced by the oxygen pressure. 


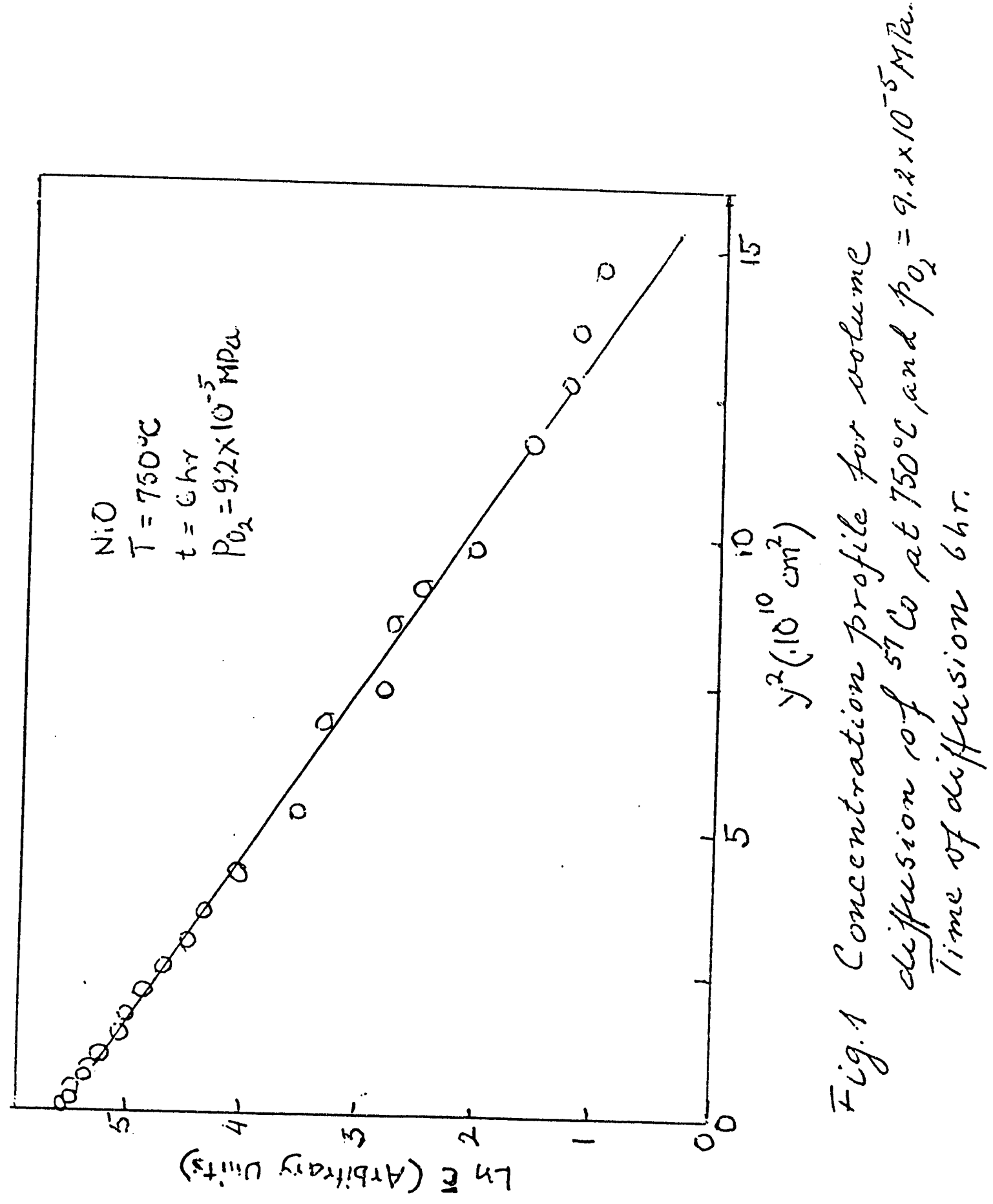




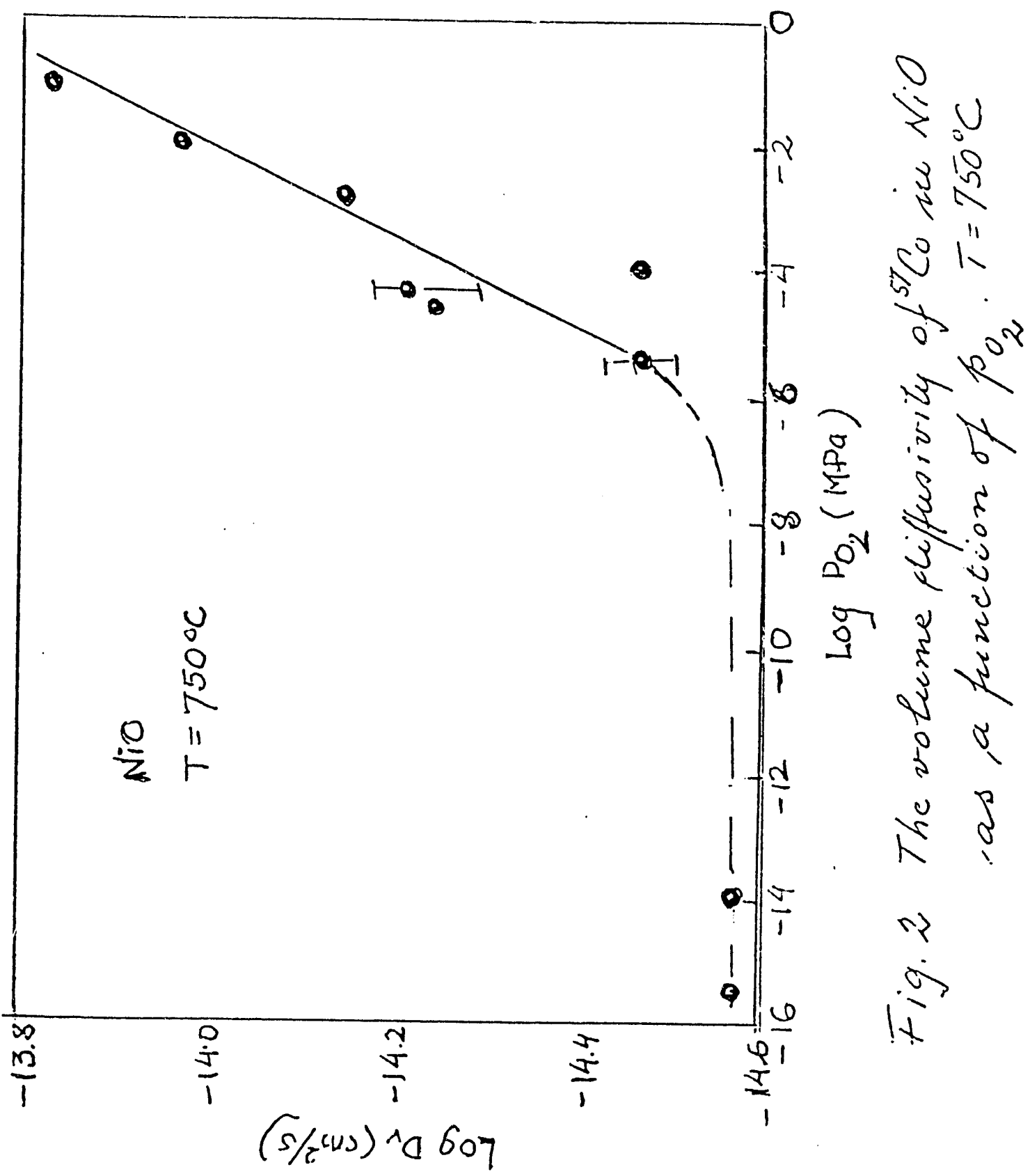




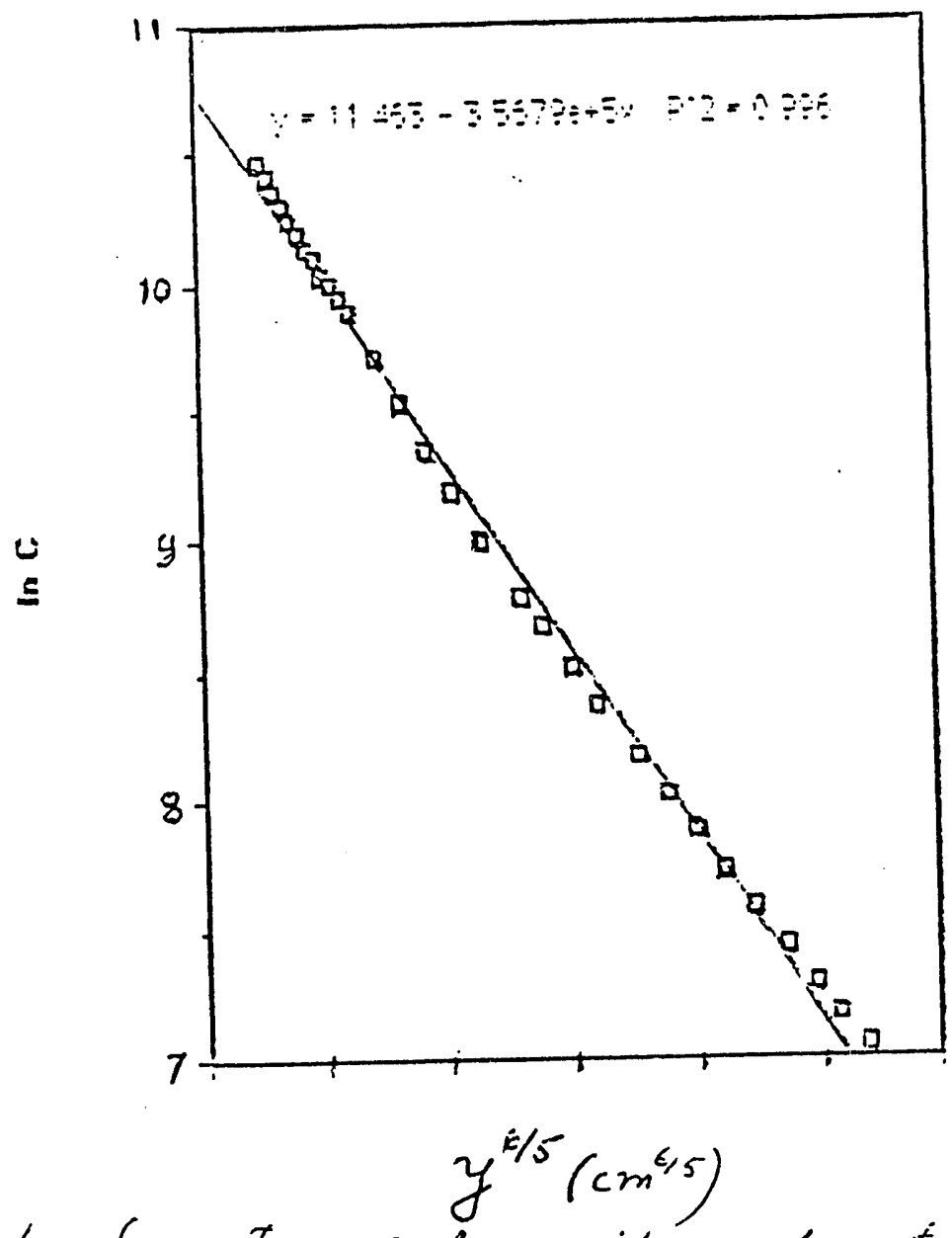

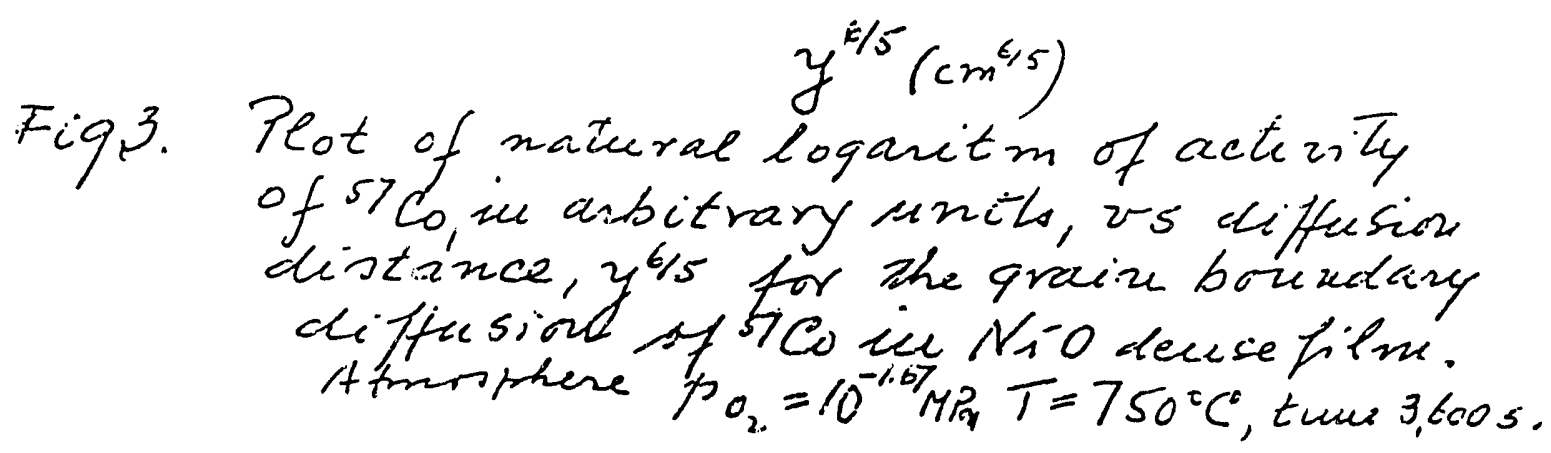




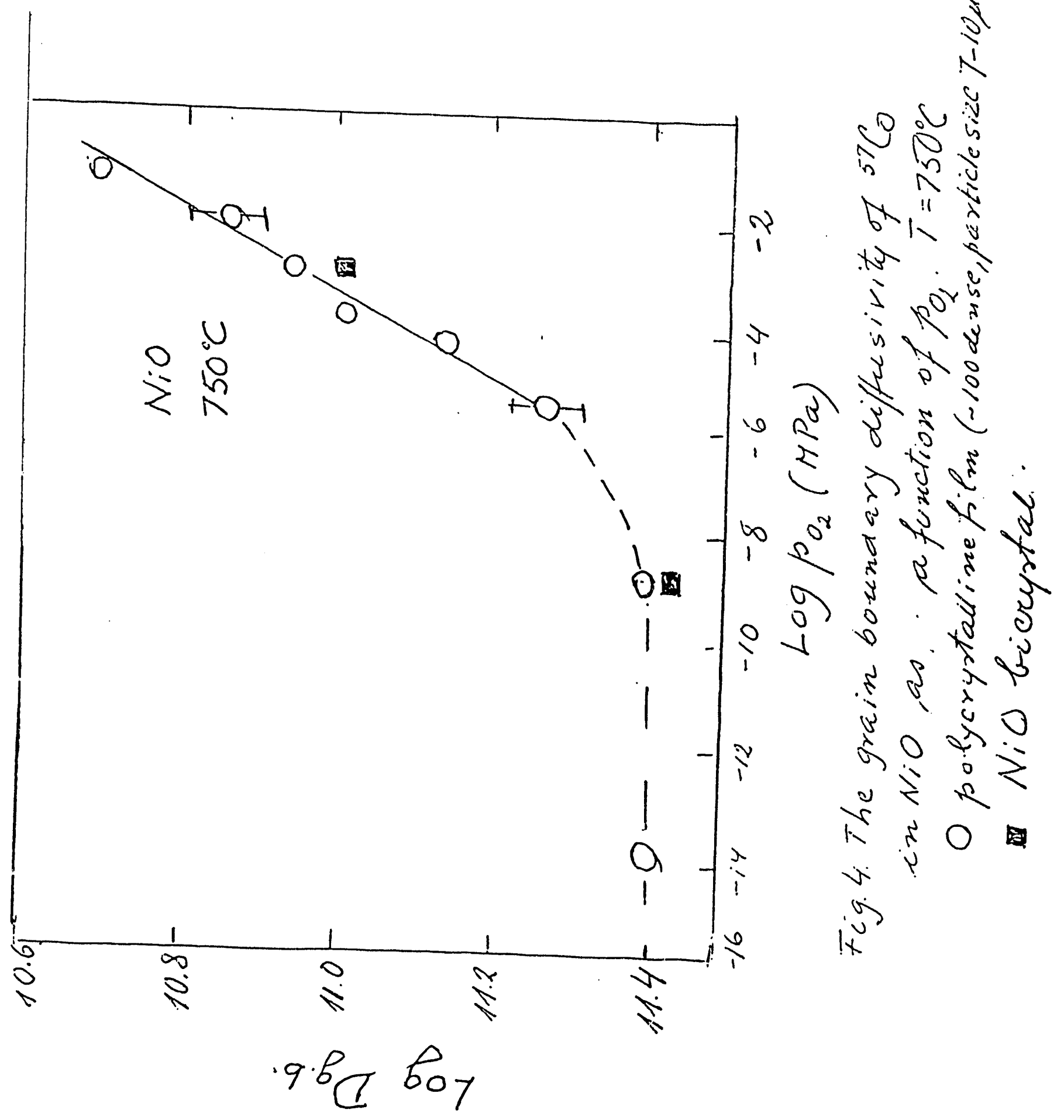




\section{Papers Published and Presented}

1. E. P. Macey and V. S. Stubican, "Diffusion of ${ }^{57} \mathrm{Co}$ in the Surface Layers of Alumina and Nickel Oxide" submitted for publication to J. Am. Ceram. Soc. (manuscripy (enclosed). cha Supported by DOE Grant No. DE-FG02-85ER45180 and Grant No. DE-FG02-90ER45414.

2. V. S. Stubican, "Influence of Nonstoichiometry on Grain Boundary and Surface Diffusion in Oxides," Invited talk presented on the Symposium 93rd Annual Meeting Am. Ceram. Soc., Cincinnati, 1991. 
DATE FILMED $11 / 25 / 92$ 
